\title{
Characteristics and Influence of Multimedia Technology on Dance Choreography
}

\author{
Liu Yang1* Zhengxi Qian² \\ ${ }^{1}$ Faculty of Music and Performing Arts, Sultan Idris Education University, Tanjung Malim, Malaysia \\ ${ }^{2}$ College of Arts, Hunan University of Arts and Sciences, Changde 415000, China \\ *Corresponding author: Liu Yang, P20192001144@siswa.upsi.edu.my
}

Copyright: (C) 2022 Author(s). This is an open-access article distributed under the terms of the Creative Commons Attribution License (CC BY 4.0), permitting distribution and reproduction in any medium, provided the original work is cited.

\begin{abstract}
In contemporary times, with the development of multimedia technology, especially in consideration of the advantages of multimedia technology in performance, dance, as an expressive art, is bound to be concatenated with multimedia technology to enrich its form of display. The influence of multimedia technology in dance choreography on dance works and the effect of multimedia technology itself on dance choreography are worth further discussion. There is no doubt that with the application of multimedia technology in the dance field, choreographers have more open and creative ideas. Perhaps, in view of the role of multimedia technology in dance creation, the involvement of various disciplines and different technologies in dance choreography would expand in the future. However, it is necessary to consider the integration of new technologies, especially the negative impact of their improper use on the expression of dance works. Therefore, this study aims to explore the elements and relations between multimedia technology and dance choreography in the new era, seek for methods and rules of multimedia technology in dance creation, pursue its positive significance, and provide certain theoretical reference for the creation of dance works through multimedia technology.
\end{abstract}

Keywords: Multimedia technology; Dance creation; Dance choreography

Online publication: January 20, 2022

\section{Introduction}

In recent years, many dance choreographers are into multimedia technology in order to achieve their desired art effect. It is possible to appreciate the emergence of many new multimedia technologies and applications, such as the human body thermal technology and the human motion capture technology, which have gradually appeared on stage. The emergence of new technologies has greatly advanced dance works, making them more infectious and bringing surprises as well as a strong sense of stage experience for the audience. At the same time, the application of these technologies has promoted a further development of stage art. With its flexibility, convenience, and richness, choreographers have gained more creative ideas and means; in addition, innovative dance works have been produced in large numbers. Unfortunately, along with the deep integration of multimedia technology into dance, its negative influence is gradually emerging. Obviously, the excessive or improper use of the technology has influenced and hindered dance itself. Professor Liu Chun pointed out that when digital technology is applied to the physical body and spirit, people intuitively see this species as "cold." Therefore, this study explores the characteristics of multimedia technology in the new era and its influence on dance creation. 


\section{Characteristics of multimedia technology in dance creation}

Multimedia technology, as a high-quality intermediary, has been integrated into many fields, including medical care, science, education, communication, and other fields; of course, dance choreography is no exception ${ }^{[1]}$. In terms of creation methods, multimedia technology provides inspiration and possibilities for dance creation, greatly enriching the ideas of creation and the presentation form of works. Usually in dance creation, the application of multimedia technology can be divided into hardware application and software application. This study mainly refers to the use of more hardware multimedia equipment. First, light-emitting diode (LED) display technology, as the main hardware in dance creation, is often used to replace the traditional stage setting. The creative use of electronic screens has been on the radar of dance artists since the 1960s. The combination of LED screen and dance art creates more possibilities for dance creation. However, in view of the defects of the LED technology itself, such as the existence of a strong sense of granularity, a small area of individual pixel light, and other shortcomings, the smooth interface of industrial projectors and the flexible choice of projection media have become more popular. Projection technology has been continuously applied to stage performance and used by choreographers ${ }^{[2]}$. Through projection, movements are decomposed and rearranged infinitely; in that way, it enhances the visual appeal, and the audiences would gain a new visual experience. At the same time, the expression of the dance content allows the audience to have unlimited imagination for a certain work. It does not only clearly express the content of the dance work, but also produce a rich artistic experience and provide a strong visual impact for the audience. There is no doubt that this is a bold attempt and practice of choreographers in the application of multimedia technology.

In terms of features, first of all, there is no doubt that the application of multimedia technology brings great convenience to dance choreography and makes it more efficient. Specifically, it brings more convenience to the operation of various stage props, thus greatly saving the operation time and requirements for various props. The second is flexibility; it brings convenience to the director to adjust and request with immediacy through the computer or console. Finally, the application of multimedia technology concentrates the original complex sound, lighting, installation, video, and other media on the console; the application of computer programming processing helps in the quick response to the needs of the director, thus better serving artistic creation ${ }^{[3]}$. At the same time, the integrated equipment has greatly enriched the content of dance editing and creation, providing more inspiration and ideas for dance creation.

\section{Multimedia "image technology" as an example in the application and development of dance choreography}

As a creative element, multimedia technology has progressed from simple to complex, from single to rich in dance creation, and developed unique styles of dances, such as dance videos, multimedia dance, and so on. Since the birth of television art in the 1960s, with the development of portable video cameras, choreographers have been trying to combine various multimedia technologies with dance to explore new creative ideas and space. "Image technology" is taken as an example to discuss the development of dance creation.

Liu believes that "image technology" is a process from camera shooting to editing and then to presentation ${ }^{[4]}$. Its application has brought great changes to dance choreography and refreshed the audience's feelings about the traditional forms of performance. With the continuous integration of image technology in dance creation, its rich forms provide continuous vigor for dance creation. In the late 20th century, with the increasing use of digital video technology, video technology has been continuously integrated into dance in order to record and disseminate dance. Dance became savable from unsavable and 
can be constantly edited and created. This has successfully laid a solid foundation for the creation of dance videos as many choreographers began to appreciate the function and effect of videos. From then onwards, videos gradually became an important part of the editing and creation process. Among them, a representative one is Maya Aren, a dance master, who created the technique of "montage" through the splicing of shots and movements, creating more perspectives for dance presentations. Later, modern dance choreographer, Trisha Brown, created a work called "Man Walking Down the Side of a Building" by using lens and installation, which opened a new door for dance choreography and put aside the influence of time, space, and characters, thus enabling one to reach a more open environment for creation.

\section{Problems arising from the application of multimedia technology in dance choreography in the new era}

Philosopher Walter Bendix Schönflies Benjamin mentioned about the aura of an artwork and that art is a unique product of immediacy. In fact, the excessive application of technology is distracting for art itself, making it lose its value. True works of dance art cannot be reproduced by technology. The reproduction of art by science and technology is bound to lose its spiritual expression because emotions are unique products of human beings and a unique art. In the creation of dance, the possibility of dance losing its spiritual charm due to the excessive intervention of multimedia technology is an issue, in which the answer to this issue has been agreed on. The use of technology in any stage performance should aid the expression of "spirit," instead of distracting its expression. It is the art rather than the technology which strikes a chord in people's hearts. The proper application of this technology, the avoidance of the phenomenon of insufficient drama, and the use of multimedia to assist artistic creation to fully express its own spirit and unique value are worthy of attention and reflection as multimedia dance works that can withstand the test of history often need a long time through technology and stage art.

\section{Multimedia technology should serve dance ontology in dance creation}

As one of the most important carriers of art, dance reflects refined, organized, and beautified human movements. Therefore, the expression of "borrowed limbs" is the core of dance art ${ }^{[5]}$. Multimedia technology can be used as a part in the formation of dance vocabulary, creating the atmosphere and as an auxiliary expression. For example, the diversified and innovative presentation of lightings, sounds, and vision from multiple angles makes the expression of the body movements more appropriate and natural; however, the most important measure is that the application of the technology does not affect the expression of the dancers' movements. The application of the technology to enhance the body tension should always be in an auxiliary position. Choreographers need to pay more attention to the routes and movement rules of the dancers' bodies as well as try to use less flashy ways to attach them on the dancers, so that the dazzling scenes would not make the audience lose focus on the dance itself. It is important to pay full attention to the mood of the dancers, the turning point of the movement, and the grasp of the rhythm on the premise of understanding the rules of the movements in the appropriate place to integrate multimedia elements in creating a stage effect of twice the result with half the effort. The proper use of multimedia technology is able to beautify works. From the perspective of enhancing visual impact, the application of rich multimedia effects and the addition of photoacoustic technology as well as light and shadow art can indeed enhance the visual effect of the works and play excellent supplementary roles in rendering the stage atmosphere and reproducing real scenes, which can fully meet the visual needs of the audience. However, the expression of the content should still occupy the main position, with technology as a support or aid. The excessive emphasis on technology in visual exhibition may "seize the eye" sooner or later because of technical means, thus losing the meaning of dance art itself. Liu Chun believes that the development of technology in the 
field of performance is not an attempt to change or destroy the traditional theater but to push the concept of space in performance and theater into an unprecedented area ${ }^{[6]}$. Technology should be used to explore life and seek inspiration, rather than to boast. The expression of the real connotation of a work can infuse more vitality to the work, and the clear relationship between primary and secondary can make the expression of the work more prominent. The design and creation should conform to the stage principle, so that the works can achieve rich visual experience without losing the expression of real contents and emotions.

All in all, the creation and presentation of a good dance work is a perfect combination of technology and art. The unique expression of ideas, rich emotional expression, and profound accumulation of aesthetic knowledge are indispensable. The production and application of new technologies under the new era are the trends of the times. The dance subject should not be lost under the premise of multimedia technology. It should not only be used for innovation of art forms, making the content richer, but also to distinguish primary from secondary with more appropriate application and to master the law of dance through a reasonable method for the expression of dance art.

\section{Disclosure statement}

The authors declare that there is no conflict of interest.

\section{References}

[1] Yang J, 2018, Discussion on the Promotion Effect of Modern Multimedia Technology on the Development of Dance. Strait Science, 2018(03): 84-86.

[2] Ji C, 2016, Study on Aesthetic Relationship Between Dance Art and Body. Drama Home, 2016(21): 136.

[3] Walter B, 2002, Art works in the Age of Mechanical Reproduction, China City Press.

[4] Liu R, 2004, Digital Dance, Beijing Art Review.

[5] Zhang Z, 2019, The Radio Wave That Never Dies: The Resounding Response of Dance Drama Art in the New Era. Art Review, 2019(07): 144-147.

[6] Han S, 2008, Introduction to Stage Design, Culture and Art Publishing House, 8.

[7] Pan Y, 2015, Research on Multimedia Presentation of Dance. Minzu University of China.

[8] Li D, 2004, Dance Multimedia Technology and Its Application (First Edition), Shanghai Music Publishing House, 9. 